Article

\title{
Research on the International Roughness Index Threshold of Road Rehabilitation in Metropolitan Areas: A Case Study in Taipei City
}

\author{
Shong-Loong Chen ${ }^{1}{ }^{\mathbb{D}}$, Chih-Hsien Lin ${ }^{1}$, Chao-Wei Tang ${ }^{2,3,4, *}$, Liang-Pin Chu ${ }^{5}$ \\ and Chiu-Kuei Cheng ${ }^{6}$ \\ 1 Department of Civil Engineering, National Taipei University of Technology, 1, Sec. 3, Zhongxiao E. Rd., \\ Taipei 10608, Taiwan; f10391@ntut.edu.tw (S.-L.C.); richman0145@gmail.com (C.-H.L.) \\ 2 Department of Civil Engineering and Geomatics, Cheng Shiu University, No. 840, Chengching Rd., \\ Niaosong District, Kaohsiung 83347, Taiwan \\ 3 Center for Environmental Toxin and Emerging-Contaminant Research, Cheng Shiu University, \\ No. 840, Chengching Rd., Niaosong District, Kaohsiung 83347, Taiwan \\ 4 Super Micro Mass Research and Technology Center, Cheng Shiu University, No. 840, Chengching Rd., \\ Niaosong District, Kaohsiung 83347, Taiwan \\ 5 Taipei City Government, No. 1, City Hall Rd., Xinyi District, Taipei City 110204, Taiwan; \\ bk_102107@mail.taipei.gov.tw \\ 6 Department of Agribusiness Management, National Pingtung University of Science and Technology, \\ No. 1, Shuefu Rd., Neipu, Pingtung 91201, Taiwan; sindy@mail.npust.edu.tw \\ * Correspondence: tangcw@gcloud.csu.edu.tw; Tel.: +886-7-735-8800
}

Received: 24 October 2020; Accepted: 14 December 2020; Published: 16 December 2020

\begin{abstract}
The International Roughness Index (IRI) is the standard scale for evaluating road roughness in many countries in the world. The Taipei City government actively promotes a Road Smoothing Project and plans to complete the rehabilitation of the main and minor roads within its jurisdiction. This study aims to detect the road surface roughness in Taipei City and recommend appropriate IRI thresholds for road rehabilitation. A total of 171 asphalt concrete pavement sections in Taipei City with a total length of $803.49 \mathrm{~km}$ were analyzed and compared by IRI. The longitudinal profile of the detected road sections was measured using an inertial profiler. The statistical analysis showed that the IRI value prior to road leveling was mainly distributed between 5 and $8 \mathrm{~m} / \mathrm{km}$, while the IRI value after road leveling was mainly distributed between 3 and $4.5 \mathrm{~m} / \mathrm{km}$. This confirms that the implementation of the Road Smoothing Project has a significant effect on improving road smoothness. Moreover, based on the analysis results, it is recommended that the IRI threshold value for road rehabilitation in Taipei City be set at $4.50 \mathrm{~m} / \mathrm{km}$.
\end{abstract}

Keywords: pavement smoothness; international roughness index; urban road; road rehabilitation

\section{Introduction}

Cities are areas with a high density of living environments and active economic activities. Due to human communication and economic activities, urban roads are usually planned as interconnected networks. Basically, urban roads are composed of roadways, sidewalks, green belts, drainage systems, transportation facilities, intersections and auxiliary facilities. Generally speaking, urban road design needs to meet the traffic characteristics and traffic needs of its service objects (people, goods, cars, etc.). The pros and cons of road service performance are often reflected in the quantity, quality, and form. In other words, the scale of road construction should be sufficient, the road structure can ensure safe driving, the road network layout and road alignment should be reasonable, and the auxiliary facilities 
and management standards should be matched. Therefore, providing complete roads and good service performance is not only one of the important functions of modern cities, but also the foundation of sustainable urban development.

Roadways can be divided into flexible pavements and rigid pavements according to their structural properties [1]. In a flexible pavement, the wheel loads are transferred by grain-to-grain contact of the aggregate through the granular structure. This kind of pavement usually adopts a multi-layer design; from bottom to top, there are the subgrade (also known as the bed), subbase course, base course, and surface course. In a rigid pavement, the wheel loads are transferred to the subgrade soil through the bending strength of the pavement, and the pavement is like a rigid slab (such as a cement concrete pavement). Overall, the flexible pavement has proper bending resistance and sufficient stability to support the traffic load. As a result, urban roadways are mostly designed with flexible pavements. Pavement smoothness (sometimes termed roughness) is commonly estimated using a pavement profile (a measure of minute elevation changes in the pavement surface). According to a survey conducted by the Federal Highway Administration in 2002 [2], pavement smoothness is regarded as the most important indicator of user satisfaction. Since pavement smoothness is an important factor affecting the performance of roadway services, many researchers have been engaged in this field [3-27]. Commonly used pavement smoothness indicators include the International Roughness Index (IRI), Profile Index (PI), Maysmeter Index (MI), Root Mean Square Vertical acceleration (RMSVA), and Ride Number (RN), etc. In addition, because pavement service capacity is mainly affected by roughness, pavement performance indicators such as Present Serviceability Index (PSI) or Present Serviceability Rating (PSR) are also used to represent pavement roughness [4,8]. Regardless of the index, the goal is to mathematically reflect the level of comfort experienced by users while driving.

Taipei City is located in the Taipei Basin in northern Taiwan. It is the central city of the Taipei Metropolitan Area and northern Taiwan, and it is also an international city. Roads in Taipei City can be divided into express roads, main roads, secondary roads, and branch roads. Among them, express roads and main roads are the backbones of urban traffic, ensuring the connectivity of various areas in the city, while secondary roads and branch roads function as auxiliary main roads to ensure the accessibility of the regional road network. Urban roads are the facilities that most directly affect the experience of pedestrians, the quality of driving, and the safety of driving. They must have the characteristics of stability, comfort, and safety, and provide the service quality that satisfies road users under moderate maintenance. Therefore, how to maintain road quality with limited maintenance funds has become an important issue for relevant authorities. If a systematic method can be used to manage the pavement, the limited engineering funds will be able to maximize the benefits and maintain the service level of the overall road network.

For the sustainable development of the city, the Taipei City government has conducted the Road Smoothing Project since 1998 to improve the quality of roads under its jurisdiction. In addition to the smoothness test of the original asphalt concrete pavement before it is demolished, after the new asphalt concrete pavement of the road is completed, the smoothness test is conducted in conjunction with the supervision department and the construction manufacturer. However, compared with the U.S. states that currently use IRI values to assess road conditions and control the construction quality of individual highway projects, the threshold set by Taiwan's current laws and regulations has room for adjustment. Furthermore, it has been mentioned in many previous documents that a higher initial roughness not only shortens the service life of the pavement but also increases the number of rehabilitations [11]. On the other hand, due to the low speed on urban roads, comfortable driving can still be achieved under high IRI values. It is necessary to determine the acceptable IRI threshold for urban roads with various speed limits.

Due to heavy traffic, the high frequency of pipeline excavation, and inaccurate backfilling, the rate of damage to the roads in Taipei City has accelerated, which not only increases the burden of maintenance work but also causes many human casualties. From this perspective, the implementation of quality maintenance work and the maintenance of good road service performance are urgent tasks of 
the Taipei City Government. In view of the above, this study aims to detect the road surface smoothness in Taipei City and examine the threshold values of acceptance for pavement surface characteristics to clarify whether there is room for adjustment of the current regulations.

\section{International Roughness Index}

\subsection{The Analysis Mode of International Roughness Index}

The IRI value was proposed by a study promoted by the World Bank in the 1980s [8]. It is calculated by using the dynamic response of vehicles to calculate the road profile, and then simulated by the so-called quarter car system. The quarter car simulation model consists of two parts: A sprung mass and an unsprung mass, as shown in Figure $1[9,14]$. The former represents the vehicle body, while the latter represents the set of wheel/tire and half axle/suspension. The sprung mass is connected to the unsprung mass through the suspension, and the suspension is simulated by a damper and a spring. In this model, the sprung and unsprung masses that correspond to one corner of the vehicle are represented by $m_{s}$ and $m_{u}$, respectively. The suspension system is denoted by a linear spring with a stiffness of $k_{s}$ and a linear damper with a damping rate of $c_{s}$, while the tire is modelled by a linear spring with a stiffness of $k_{t} . y$ represents the input of road unevenness. In the simulation process, the quarter car system drives on the longitudinal profile of the test road. The profile is measured in the field at a constant speed of $80 \mathrm{~km} / \mathrm{h}$. The roughness on this surface causes dynamic excitation of the quarter car system, resulting in different vertical speeds $\left(\dot{Z}_{s}\right.$ and $\left.\dot{Z}_{u}\right)$ or accelerations $\left(\ddot{Z}_{s}\right.$ and $\left.\ddot{Z}_{u}\right)$ in the sprung and unsprung masses. The result is a relative movement between the chassis and the wheel-axle of the imaginary vehicle. The vertical acceleration can be measured using accelerometers mounted on the body and front axle (or rear axle) of the vehicle. The transducer converts the strain of accelerometers into an electrical signal. By drawing free body diagrams and applying Newton's Second Law, we get the following differential equations $[9,14]$ :

$$
\begin{gathered}
m_{s} \ddot{Z}_{s}+c_{s}\left(\dot{Z}_{s}-\dot{Z}_{u}\right)+k_{s}\left(Z_{s}-Z_{u}\right)=0 \\
m_{s} \ddot{Z}_{s}+m_{u} \ddot{Z}_{u}+k_{t}\left(Z_{u}-y\right)=0
\end{gathered}
$$

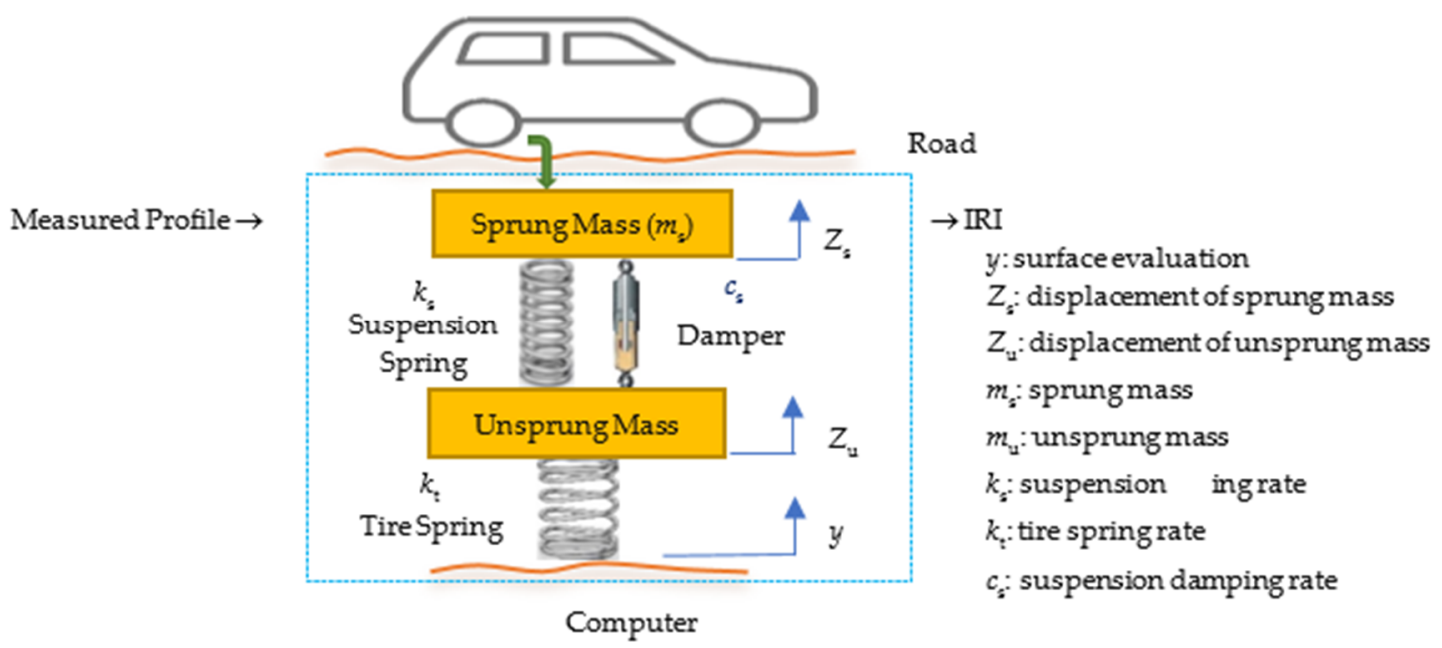

Figure 1. Illustration of computer algorithm used to compute the International Roughness Index (IRI) $[9,14]$.

Dividing both sides of Equations (1) and (2) by $m_{s}$ at the same time, the equations of motion can be simplified to Equations (3) and (4):

$$
\ddot{Z}_{s}+C\left(\dot{Z}_{s}-\dot{Z}_{u}\right)+K_{2}\left(Z_{s}-Z_{u}\right)=0,
$$




$$
\ddot{Z}_{s}+u \ddot{Z}_{u}+K_{1} Z_{u}=K_{1} y
$$

where $C=c_{s} / m_{s}=6(1 / s) ; u=m_{u} / m_{s}=0.15 ; K_{1}=k_{t} / m_{s}=653\left(1 / s^{2}\right) ; K_{2}=k_{s} / m_{s}=63.3\left(1 / s^{2}\right)[9]$. The National Cooperative Highway Research Program (NCHRP) research led to specific set of parameters for a quarter-car computerized response system, called the Golden Car [9]. The name was intended to convey that this computer representation was a calibration reference. The vertical displacement change of the vehicle can be obtained through quadratic integration, and then the distance between the vehicle and the pavement measured by the displacement sensor is added or subtracted to obtain the longitudinal profile elevation data of the pavement. Therefore, the IRI value for a given road section length can be calculated according to Equation (3) $[9,14,28-30]$.

$$
\mathrm{IRI}=\frac{1}{L} \int_{0}^{L}\left|Z_{s}-Z_{u}\right| d x,
$$

Here, IRI = International Roughness Index $(\mathrm{m} / \mathrm{km}) ; L=$ length of the section $(\mathrm{km})$. Equations (3) and (4) are the simplest differential equations of motion corresponding to the vehicle model. They are described in the time domain $t$, that is, all variables such as $Z_{s}, Z_{u}$ and their derivatives and $y$ are functions of time. From the above analysis, we can see that IRI is achieved by solving Equations (3) and (4). There are many ways to solve the differential Equations (3) and (4), either analytical methods or numerical methods (such as Taylor Series Expansion, Euler's Method, Second and Fourth Order Runge-Kutta) can be used $[28,29]$. Due to the discontinuity of the elevation function of the road section, it is difficult to express it with a unified mathematical function. Therefore, the numerical method is generally used to calculate the result to get the IRI. When the World Bank proposed IRI, it gave the calculation formula of the transfer matrix method [8]. At present, this numerical calculation method is generally used when calibrating IRI.

\subsection{The Application of International Roughness Index}

The unit of the IRI is usually meters per kilometer or inches per mile [6]. At present, IRI is a common international roughness evaluation index, which has the advantages of objectively measuring the pavement smoothness and not being interfered with by human factors. It is the first smoothness index that can be widely used in different types of pavement smoothness instruments and is supplemented by a set of program software to calculate the IRI value. The American Society for Testing and Materials (ASTM) has also included it in their specifications [14], so it is more efficient, practical, and fair than other smoothness evaluation indicators. Therefore, the IRI value can generally be used as an index to evaluate the quality of smoothness, as shown in Figure 2 [9]. In particular, it has linear characteristics and can be used to compare different smoothness values and objectively detect pavement smoothness. However, the IRI thresholds used around the world vary widely [16]. This is mainly because the IRI limit value depends on the following aspects: road surface type (i.e., flexible or rigid road surface), road function category, average annual daily flow (AADT), legal speed limit, and the length of the road section considered in the IRI calculation [31]. In addition, their changes depend on new roads or the reconstruction of roads that are still in use. Among the different parameters that affect the IRI specifications, the most important is undoubtedly the maximum allowable driving speed on the road, the roughness level of which should be evaluated [31]. In view of this, some researchers proposed speed-related IRI thresholds to evaluate the ride quality [32,33]. For example, Yu et al. [33] defined five ride quality levels, based on the jolt and jerk experienced by the evaluator in the speed range of $10 \mathrm{~km} / \mathrm{h}$ to $120 \mathrm{~km} / \mathrm{h}$, and provided corresponding IRI thresholds, as shown in Table 1 . 


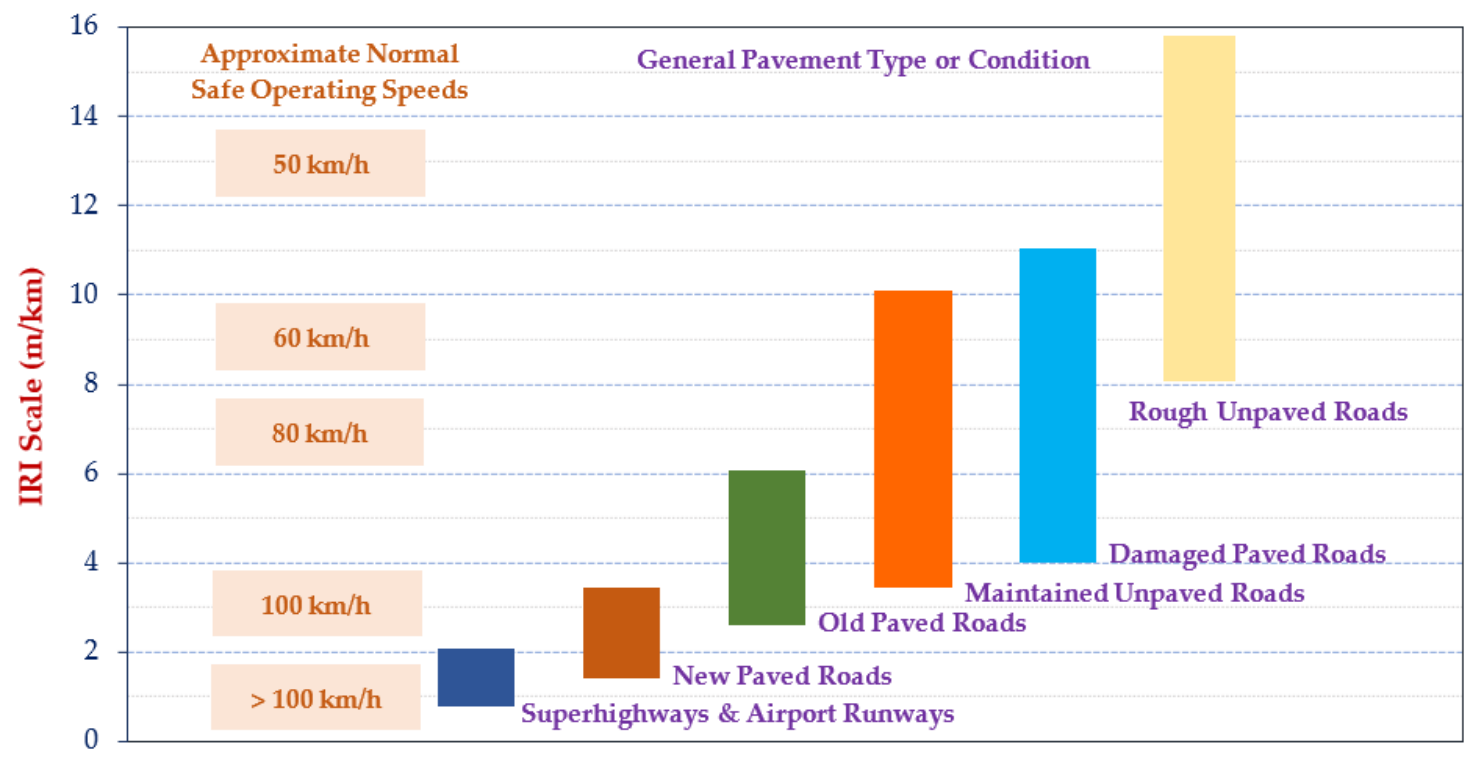

Figure 2. Illustration of the IRI scale for different pavements [9].

Table 1. Speed-related IRI thresholds at different speeds suggested by Yu et al. [34].

\begin{tabular}{ccccccc}
\hline \multirow{2}{*}{$\begin{array}{c}\text { Ride Quality } \\
\text { Level }\end{array}$} & \multicolumn{6}{c}{ IRI Thresholds at Different Speeds $\mathbf{( m / \mathbf { k m } )}$} \\
\cline { 2 - 7 } & $\mathbf{2 0}$ & $\mathbf{4 0}$ & $\mathbf{6 0}$ & $\mathbf{8 0}$ & $\mathbf{1 0 0}$ & $\mathbf{1 2 0}$ \\
\hline Very Good & $<5.72$ & $<2.86$ & $<1.90$ & $<1.43$ & $<1.14$ & $<0.95$ \\
Good & $5.72-8.99$ & $2.86-4.49$ & $1.90-2.99$ & $1.43-2.24$ & $1.14-1.79$ & $0.95-1.49$ \\
Fair & $9.00-11.39$ & $4.50-5.69$ & $3.00-3.79$ & $2.25-2.84$ & $1.80-2.27$ & $1.50-1.89$ \\
Mediocre & $11.40-16.16$ & $5.70-8.08$ & $3.80-5.40$ & $2.85-4.05$ & $2.28-3.24$ & $1.90-2.70$ \\
Poor & $>16.16$ & $>8.08$ & $>5.40$ & $>4.05$ & $>3.24$ & $>2.70$ \\
\hline
\end{tabular}

With the rapid advancement of science and technology, the techniques and methods used to measure road roughness are constantly innovating. A variety of roughness measurement instruments have been developed internationally. Bridgelall et al. [34] evaluated the increase in accuracy that can be achieved by adding standard speed bumps or existing anomalies to standard locations to enhance conventional geofencing systems to establish reference inertial markers. Their research results indicated that transportation agencies will benefit from using connected vehicle methods to achieve a level of precision and accuracy comparable to existing laser-based inertial profilers. Zhang et al. [35] used machine learning technology to estimate the roughness category and roughness index from inertial sensors on at least two connected vehicles. Their research results showed that the classification and estimation accuracy exceed 90\%. Abeygunawardhana et al. [36] investigated the influence of road roughness on the speed patterns of different road sections under different traffic levels. The IRI measured through a smartphone application was used as an indicator of road roughness. The influence of road roughness was studied at free-flow speed (85th percentile speed) and 50th percentile speed, which was determined using the speed distribution that occurred during a specific time interval. In addition, the above behaviors were analyzed separately for junctions, mid-block sections, and horizontal curves to represent different road conditions. Moreover, remote sensing provides another method for IRI assessment. Meyer et al. [37] studied the applicability of satellite radar remote sensing data, especially the high-resolution synthetic aperture radar (SAR) data acquired in the X-band, to the network-wide mapping of pavement roughness of roads in the United States. Their research showed the capacity of X-band SAR for road surface roughness mapping. 


\section{Implementation of the Road Smoothing Project}

\subsection{Contents of the Road Smoothing Project}

New road projects in Taipei City have become saturated, so the maintenance and repair of the existing road network are becoming increasingly important and large in number. The roads under the jurisdiction of Taipei City are all urban roads, with a maintenance area of approximately 20 million square meters, of which approximately 13 million square meters are for roads over $8 \mathrm{~m}$, with the goal of rehabilitation once every 5 years; roads under $8 \mathrm{~m}$ are approximately 7 million square meters, with the goal of cyclical rehabilitation once every 10 years. The Taipei City Government actively promotes the Road Smoothing Project and plans to complete the rehabilitation of the main and minor roads within its jurisdiction in 6 years. The annual plan is to update an area of approximately 1.68 million square meters. In order to improve and maintain the overall serviceability of road systems, the order of implementation will be arranged according to the road conditions (such as road aging and damage, frequency of excavation, etc.). In this study, before and after the first phase of the Road Smoothing Project, 70 road sections in Taipei City were analyzed and compared using the IRI. In addition, in the second phase of the Road Smoothing Project, 101 road sections in Taipei City were analyzed using the IRI.

\subsection{Measuring Equipment}

During the course of half a century of development, engineers and scientists have invented several techniques and methods for measuring road roughness. With the advancement of technology, highly efficient, automated and highly repeatable inertial profilometers have been developed. In this study, an inertia profiler was used to detect the current road surface smoothness in Taipei City. The inertial profiler is a test vehicle conforming to E 950 Class I [38], of which the system architecture is divided into two parts: on-board equipment and off-board equipment, as shown in Figure 3. The laser rangefinder was mounted on the front bumper of the vehicle. The main function of the displacement sensor is to receive the vertical relative distance between the vehicle and the road, while the accelerometer measures the acceleration value where the displacement sensor is located. Using the aforementioned data and the travel distance measured in conjunction with the distance measurement instrument (DMI), the change in the longitudinal profile of the detected road survey line can be calculated. The displacement sensor, accelerometer, and DMI directly transmit the signal to the data acquisition host installed in the car, and the host transmits the data to the notebook computer via a USB cable. With GPS signal receivers and video cameras, the system can analyze numerical outputs, IRI calculations, and GPS positioning data, and perform right-of-way photography integration. This system supports a variety of GPS signal receivers and video cameras, which can record driving position and road conditions. Moreover, the calibration and validation tests were used to confirm that the inertial profiler can operate properly.

Due to the impact of the urban road environment (such as traffic lights, traffic conditions, etc.), the test vehicle may not be able to reach the simulated speed of the quarter car of $80 \mathrm{~km}$ per hour. However, it can be corrected by the analysis software developed by the software development company [39]. The analysis software system automatically detects and analyzes the longitudinal profile data at the track of the inspection wheel using high-frequency sampling, and records one data point every $25 \mathrm{~cm}$. During the detection process, the vehicle speed, travel distance, laser rangefinder measurement value, and acceleration value are displayed on the software screen in real time, and the program detects the length of the vehicle approaching the detection section (default is $100 \mathrm{~m}$ ), instantly calculating and outputting the IRI value at the wheel tracking. The calculation of IRI is based on the average rectified slope (ARS), which is a filtered rate of the cumulative suspension movement of the test vehicle divided by the distance traveled by the vehicle during the measurement. 


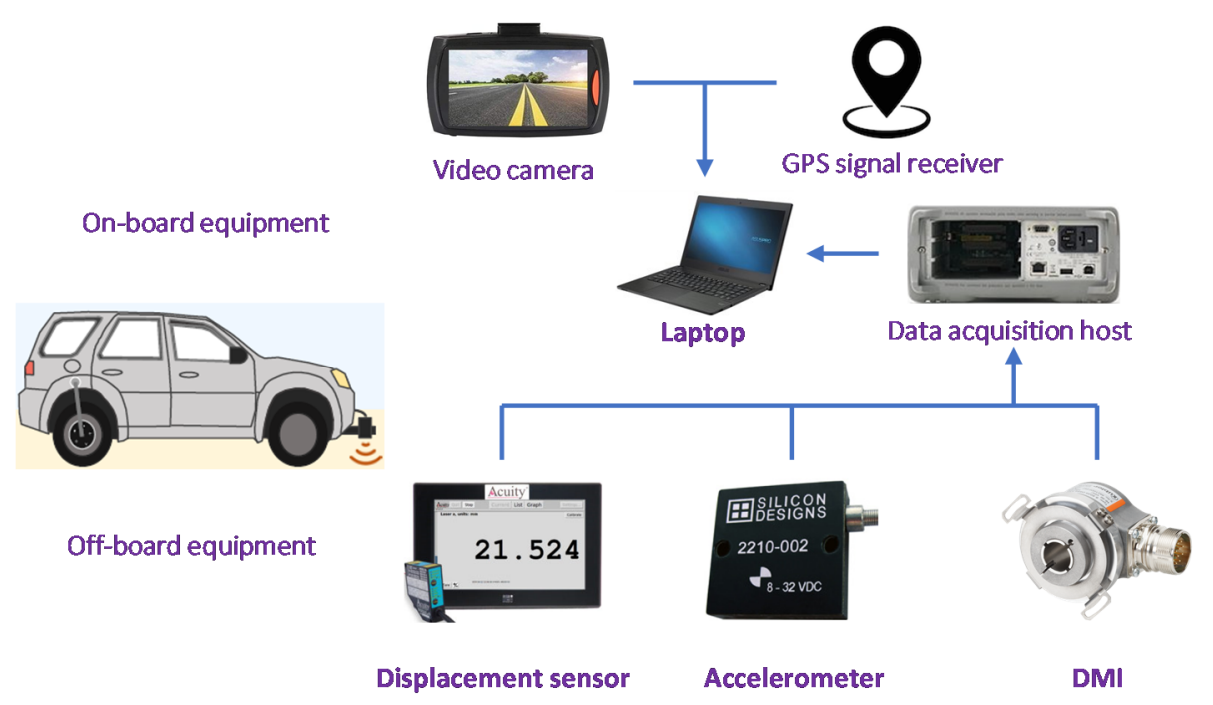

Figure 3. System architecture diagram of testing equipment.

\subsection{On-Site Inspection Method}

Before the on-site inspection operation starts, the relevant information of the inspection section must first be confirmed, including the length of the section, the number of inspection lanes, the starting and ending points of the section, etc., and the inspection operation record sheet for the use of on-site records must be created. In the actual inspection process, the inspector will turn on the inspection program system before driving into the inspection section to observe whether the readings of the various sensors are normal. At this time, the data will be regarded as the preliminary section data, and it is necessary to ensure that the detection speed is stable. When the test vehicle drives into the starting point of the inspection section, it starts to collect the smoothness data; when the test vehicle drives out of the end of the inspection section, it stops collecting data. In addition, in order to avoid excessively low vehicle speeds or unstable detection speeds due to excessive traffic volume, the detection operation will avoid the peak traffic time or arrange it to be carried out in a period of low traffic flow. The smoothness inspection operation is carried out at a stable speed under the limit of the on-site road speed limit. Furthermore, if the road area is watery, the laser rangefinder may produce scattering phenomena, which will affect the accuracy of the detection value. Therefore, the detection is carried out when there is no water on the road and the weather is good.

\section{Analysis and Discussion of Actual Measurement Results}

\subsection{Detection and Analysis of the IRI Value Before and After Road Leveling}

Since 2007, the Taipei City government has successively carried out annual IRI testing projects to conduct testing, analysis, and comparison of the IRI values of major roads before and after leveling. The detection direction of the inspection lane is divided into the forward direction (from the starting point to the ending point) and reverse direction (from the ending point to the starting point). In this study, $50 \mathrm{~m}$ was used as a detection interval, and the vehicle speed, left (left wheel tracking) IRI, right (right wheel tracking) IRI, and average IRI were recorded in the record sheet. If the interval was less than $50 \mathrm{~m}$, it was merged into the previous detection interval. Subsequently, the average IRI value was used as the basis for various statistical analyses and calculations. Take the IRI of the road number 28 before leveling as an example; the total length of the inspection was $3100 \mathrm{~m}$ (forward and reverse lanes), the average IRI value of the forward lane was $6.52 \mathrm{~m} / \mathrm{km}$, and the average IRI value of the reverse lane was $7.72 \mathrm{~m} / \mathrm{km}$, so the total average IRI value of this section before leveling was $7.12 \mathrm{~m} / \mathrm{km}$, as shown in Table 2 . 
Table 2. Inspection record of the first phase of road smoothness.

\begin{tabular}{|c|c|c|c|c|c|}
\hline \multirow{2}{*}{ Item } & \multirow{2}{*}{ Stake (m) } & \multicolumn{2}{|c|}{ Forward Lane } & \multicolumn{2}{|c|}{ Reverse Lane } \\
\hline & & $\begin{array}{c}\text { Car Speed } \\
(\mathrm{km} / \mathrm{h})\end{array}$ & $\begin{array}{c}\text { IRI } \\
(\mathrm{m} / \mathrm{km})\end{array}$ & $\begin{array}{c}\text { Car Speed } \\
(\mathbf{k m} / \mathbf{h})\end{array}$ & $\begin{array}{c}\text { IRI } \\
(\mathrm{m} / \mathrm{km})\end{array}$ \\
\hline 1 & 50 & 22.5 & 9.07 & 20.9 & 9.51 \\
\hline 2 & 100 & 28.8 & 7.36 & 18.8 & 8.49 \\
\hline 3 & 150 & 30.0 & 5.74 & 15.9 & 9.14 \\
\hline 4 & 200 & 31.8 & 6.09 & 23.9 & 9.40 \\
\hline 5 & 250 & 28.4 & 6.88 & 23.9 & 7.58 \\
\hline 6 & 300 & 21.2 & 5.57 & 22.1 & 7.39 \\
\hline 7 & 350 & 21.2 & 6.01 & 20.5 & 8.75 \\
\hline 8 & 400 & 28.0 & 4.13 & 20.3 & 9.10 \\
\hline 9 & 450 & 30.6 & 6.59 & 18.0 & 8.26 \\
\hline 10 & 500 & 31.6 & 8.35 & 19.7 & 8.12 \\
\hline 11 & 550 & 20.2 & 6.53 & 18.7 & 9.15 \\
\hline 12 & 600 & 27.2 & 7.75 & 15.6 & 6.73 \\
\hline 13 & 650 & 29.1 & 7.41 & 21.6 & 6.34 \\
\hline 14 & 700 & 29.0 & 5.69 & 20.6 & 6.72 \\
\hline 15 & 750 & 27.9 & 7.70 & 22.2 & 7.44 \\
\hline 16 & 800 & 22.2 & 7.54 & 28.1 & 7.73 \\
\hline 17 & 850 & 16.7 & 7.84 & 19.2 & 8.24 \\
\hline 18 & 900 & 15.1 & 6.78 & 20.3 & 7.77 \\
\hline 19 & 950 & 24.0 & 5.65 & 21.3 & 7.50 \\
\hline 20 & 1000 & 25.9 & 6.20 & 22.9 & 7.74 \\
\hline 21 & 1050 & 27.1 & 11.40 & 32.1 & 8.63 \\
\hline 22 & 1100 & 24.5 & 5.43 & 31.8 & 8.37 \\
\hline 23 & 1150 & 25.8 & 5.22 & 30.7 & 7.10 \\
\hline 24 & 1200 & 28.0 & 3.82 & 29.3 & 7.55 \\
\hline 25 & 1250 & 31.3 & 3.48 & 31.8 & 4.65 \\
\hline 26 & 1300 & 24.4 & 3.06 & 32.3 & 4.59 \\
\hline 27 & 1350 & 13.7 & 5.80 & 32.2 & 7.67 \\
\hline 28 & 1400 & 25.1 & 6.20 & 33.4 & 5.12 \\
\hline 29 & 1450 & 23.9 & 7.99 & 33.3 & 4.37 \\
\hline 30 & 1500 & 35.5 & 8.85 & 31.2 & 10.53 \\
\hline 31 & 1550 & 37.4 & 5.95 & 24.9 & 9.76 \\
\hline \multicolumn{2}{|c|}{ Average value } & 26.1 & 6.52 & 24.4 & 7.72 \\
\hline \multicolumn{2}{|c|}{ Standard deviation } & - & 1.73 & - & 1.52 \\
\hline \multicolumn{2}{|c|}{ Maximum value } & 37.4 & 11.40 & 33.4 & 10.53 \\
\hline \multicolumn{2}{|c|}{ Minimum value } & 13.7 & 3.06 & 15.6 & 4.37 \\
\hline
\end{tabular}

Figure 4 shows the IRI values of the 70 road sections in the first phase of the Road Smoothing Project. It can be seen from Figure 4 that the IRI data before road leveling covers a wide range of road smoothness. Statistical analysis shows that the average IRI value before leveling was $5.91 \mathrm{~m} / \mathrm{km}$, and the average IRI value after leveling was $3.84 \mathrm{~m} / \mathrm{km}$. In addition, the histograms of the calculated IRI distribution before and after road leveling are shown in Figures 5 and 6, respectively. Figure 5 shows that the IRI value before road leveling was mainly distributed between 5 and $8 \mathrm{~m} / \mathrm{km}$, while Figure 6 shows that the IRI value after road leveling was mainly distributed between 3 and $5 \mathrm{~m} / \mathrm{km}$. The IRI value of the tested road section shows a downward trend, showing that the implementation of the Road Smoothing Project has a significant effect on improving road smoothness. On the other hand, the statistical data of the test results of the 101 road sections in the second phase of the Road Smoothing Project (as shown in Figure 7) shows that the IRI value after road leveling was mainly distributed between 2 to $4.5 \mathrm{~m} / \mathrm{km}$, with an average of $3.74 \mathrm{~m} / \mathrm{km}$. Overall, the IRI value of the second phase of road leveling was smaller than that of the first phase, indicating that the quality of the road was better. 


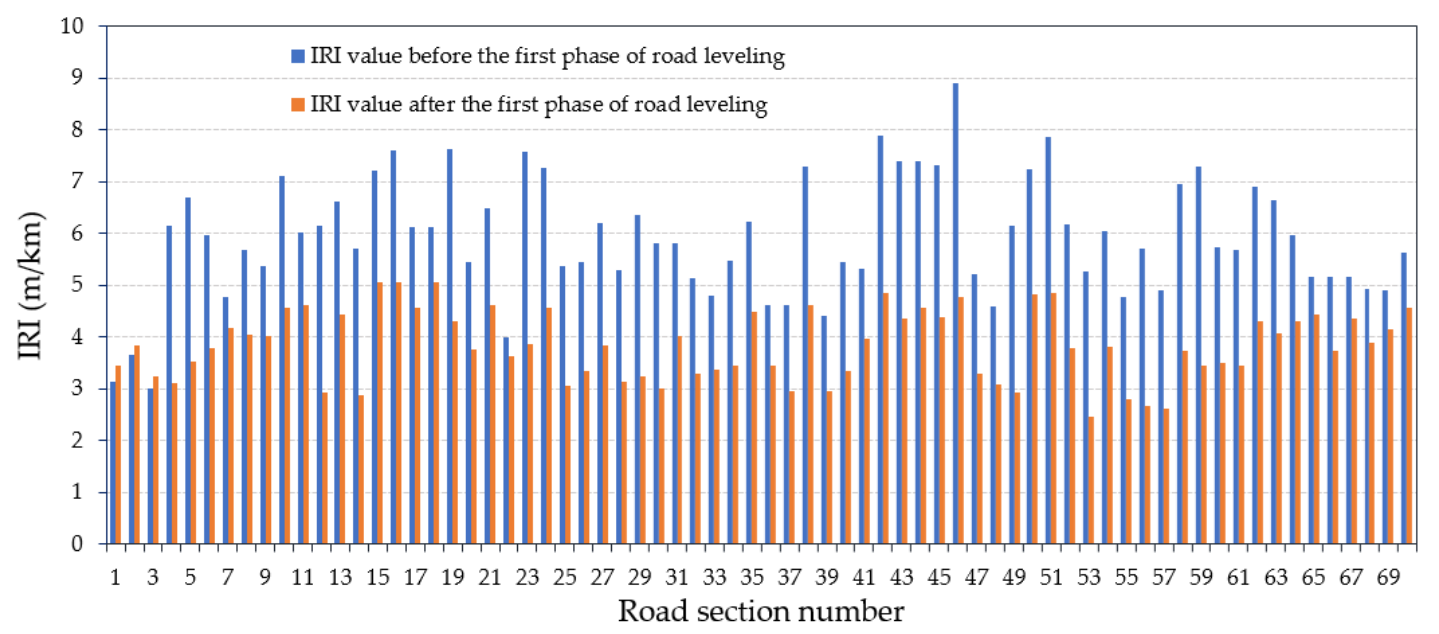

Figure 4. Comparison of IRI values before and after the first phase of the Road Smoothing Project.

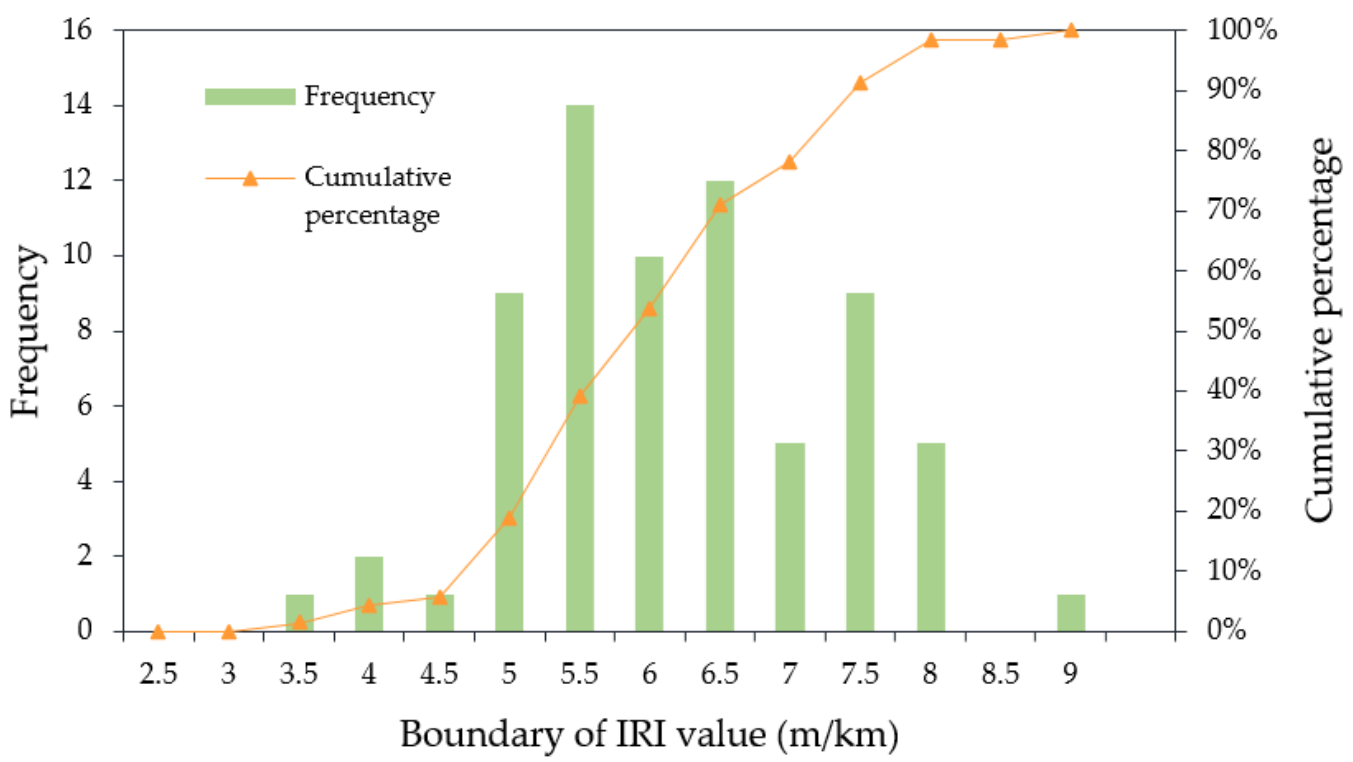

Figure 5. Histogram and cumulative curve of IRI values before the first phase of the Road Smoothing Project.

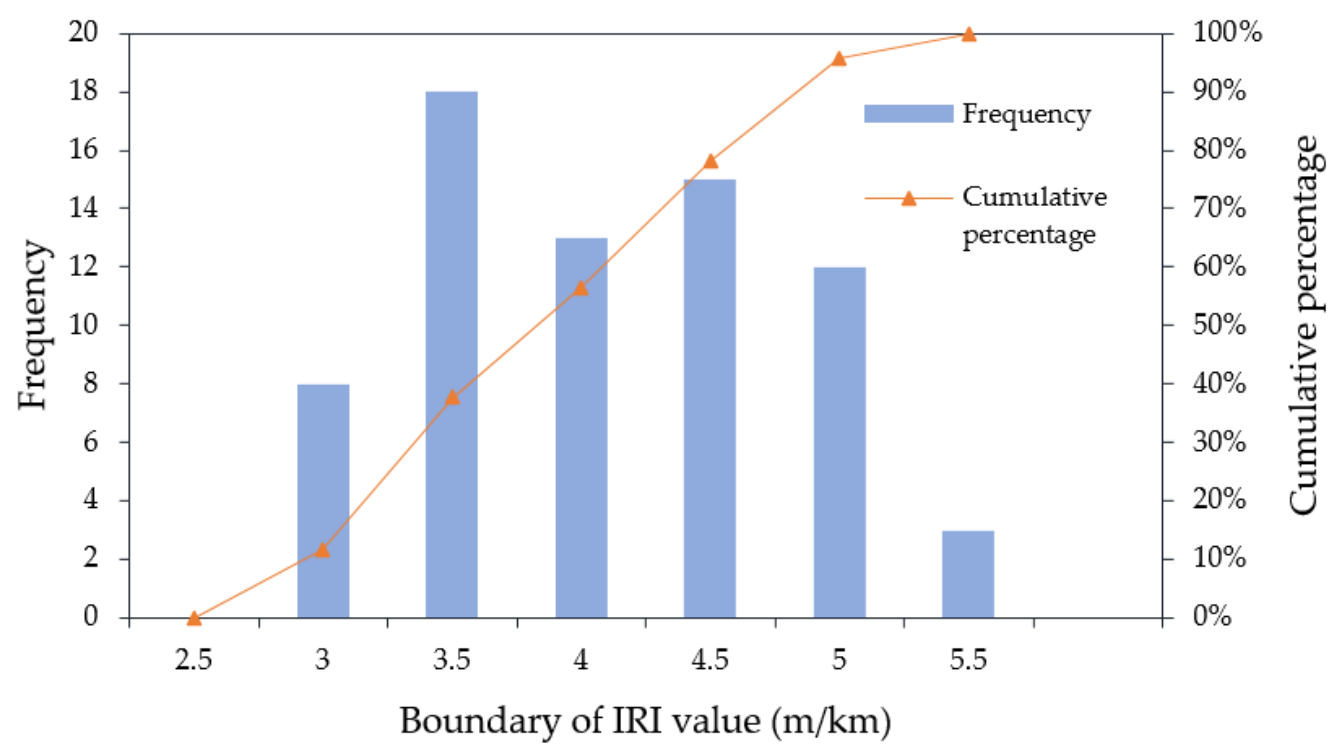

Figure 6. Histogram and cumulative curve of IRI values after the first phase of the Road Smoothing Project. 


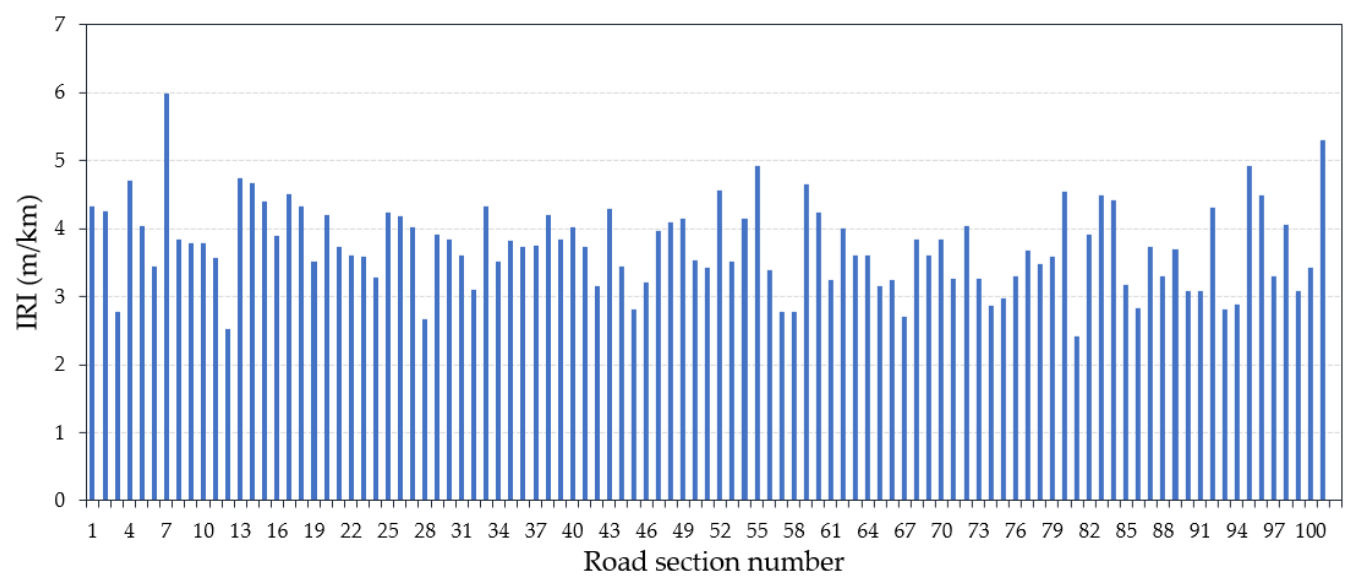

Figure 7. IRI value after the second phase of the Road Smoothing Project.

\subsection{Statistical Analysis of the IRI Value}

The average IRI value of each detected road section is a single data point. Statistical parameters such as average value, maximum value, minimum value, range, variance, and standard deviation for the data IRI values were calculated and are summarized in Table 3. The "range" in the statistical parameters is the difference between the maximum value and the minimum value of the road IRI value, and the calculated value is used to determine whether the road smoothness is good or bad. It can be seen from Figure 8 that the average value and standard deviation of the IRI of the detected road section after road leveling were significantly improved. In other words, after the road was leveled, the smoothness was improved. Therefore, as far as the inspected road sections were concerned, the quality control after road leveling was excellent. The current IRI distribution map of the main roads and minor roads in Taipei City according to the detection data of this research is shown in Figure 9. It had a considerable contribution to the judgement of construction quality.

Table 3. IRI values before and after the Road Smoothing Project.

\begin{tabular}{cccc}
\hline Statistical Parameters & $\begin{array}{c}\text { Before the First Phase } \\
\text { of Road Leveling }\end{array}$ & $\begin{array}{c}\text { After the First Phase of } \\
\text { Road Leveling }\end{array}$ & $\begin{array}{c}\text { After the Second Phase } \\
\text { of Road Leveling }\end{array}$ \\
\hline Average value $(\mathrm{m} / \mathrm{km})$ & 5.91 & 3.84 & 3.74 \\
Maximum value $(\mathrm{m} / \mathrm{km})$ & 8.89 & 5.07 & 5.98 \\
Minimum value $(\mathrm{m} / \mathrm{km})$ & 3.01 & 2.47 & 2.42 \\
Range $(\mathrm{m} / \mathrm{km})$ & 5.88 & 2.60 & 3.56 \\
Variance & 1.33 & 0.46 & 0.40 \\
Standard deviation $(\mathrm{m} / \mathrm{km})$ & 1.15 & 0.68 & 0.64 \\
\hline
\end{tabular}

\subsection{Inspection on the Appropriateness of the IRI Threshold Value for Road Rehabilitation in Taipei City}

Based on the detected results of each road section, the cumulative percentage of IRI values before and after road leveling can be calculated. Figure 10 shows the cumulative percentage curve of IRI values in the detected road. Regarding the three cumulative curves in Figure 10, the cumulative curve after road leveling shifted significantly to the left, indicating that the IRI value of the detected road sections showed a downward trend, mainly distributed from 2.86 to $4.49 \mathrm{~m} / \mathrm{km}$. Taking the road section with IRI $\leq 5 \mathrm{~m} / \mathrm{km}$ as an example, the cumulative percentage before road leveling was $14.77 \%$, and after road leveling, it increased to $94.35 \%$. 


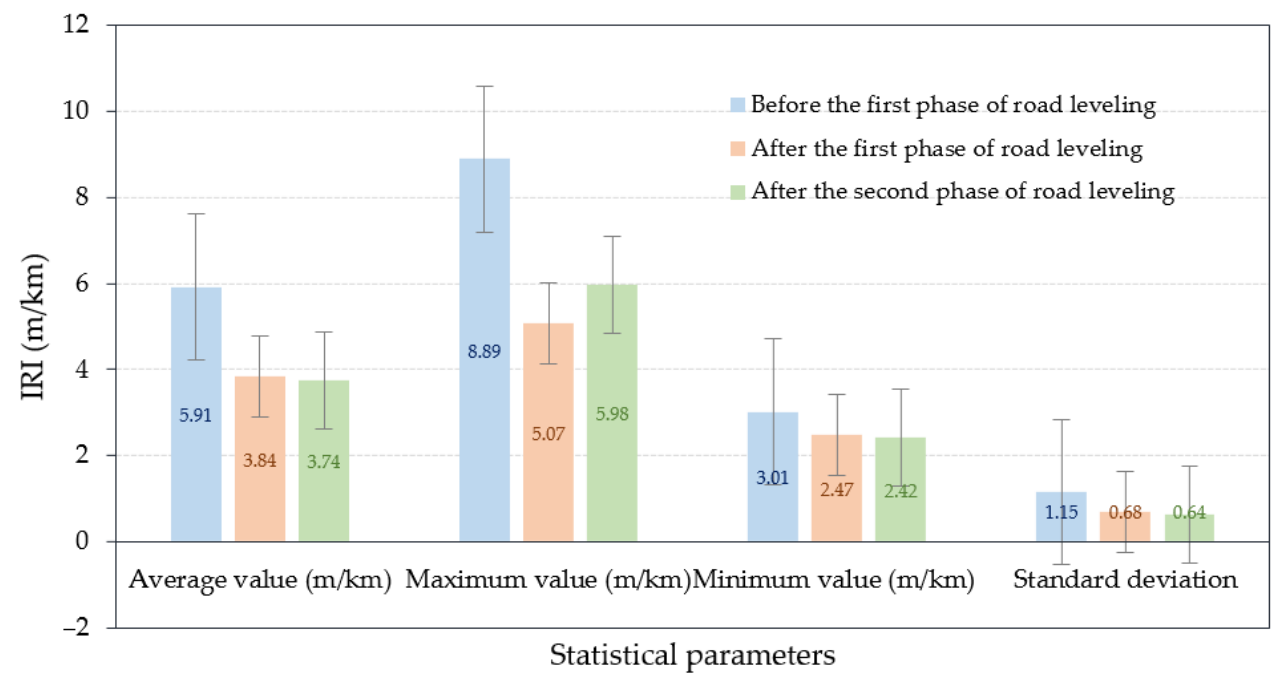

Figure 8. Comparison of IRI values before and after the Road Smoothing Project.

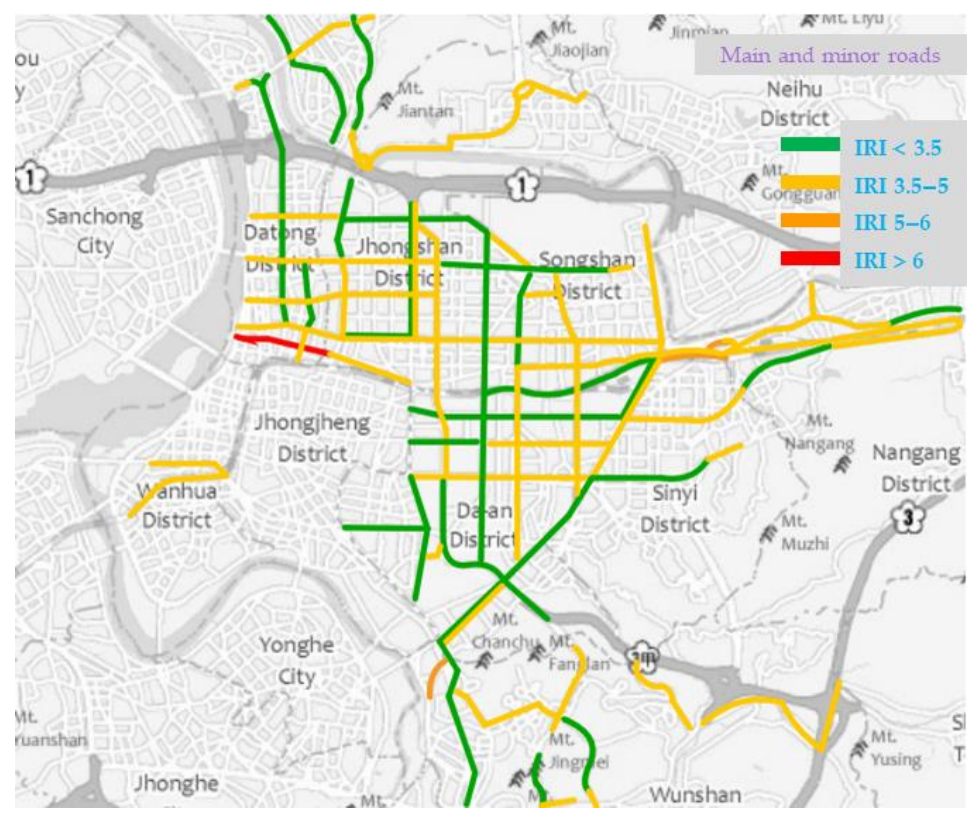

Figure 9. IRI distribution map of major and minor roads in Taipei City.

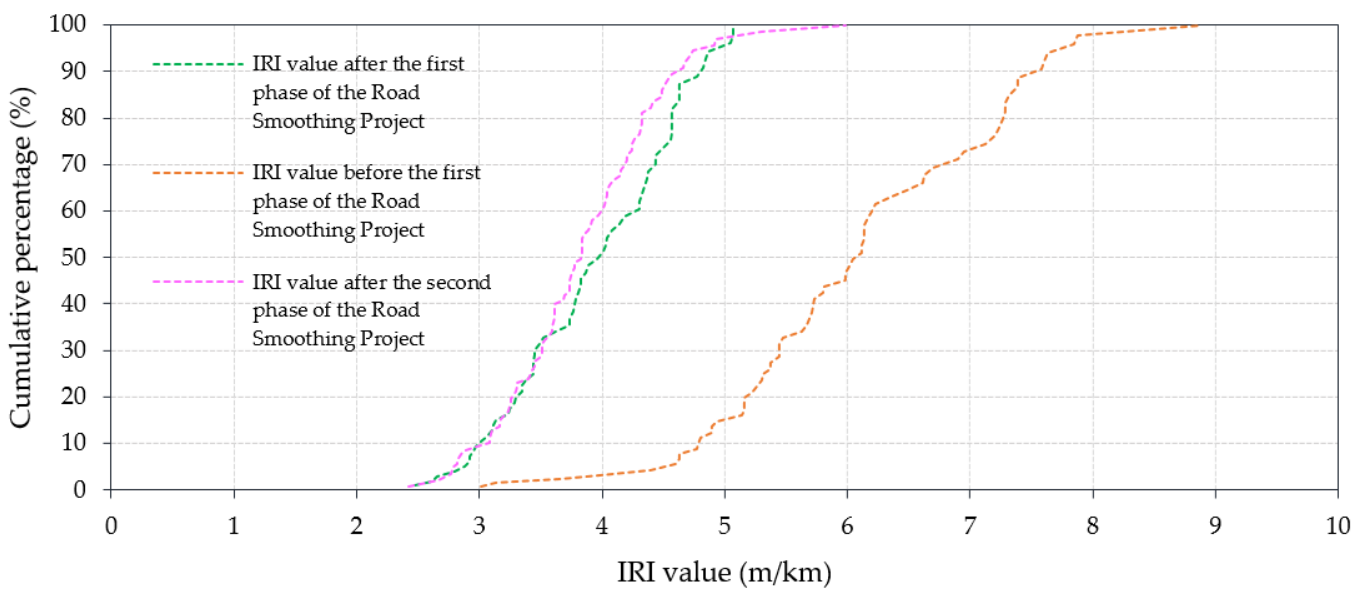

Figure 10. Cumulative percentage curve of IRI values before and after the Road Smoothing Project. 
Many countries have established IRI thresholds for road maintenance and rehabilitation scheduling. Taiwan's current pavement smoothness inspection standards are IRI $<3.5 \mathrm{~m} / \mathrm{km}$ or a standard deviation of three-meter-long straightedge $<2.4 \mathrm{~mm}$ for general roads and IRI $<1.75 \mathrm{~m} / \mathrm{km}$ or a standard deviation of three-meter-long straightedge $<2.6 \mathrm{~mm}$ for highways [40]. These two indicators have a high degree of correlation when the pavement smoothness is increased [40], which shows that the two can be interconverted in a linear manner. However, when the pavement smoothness is poor, such as an IRI greater than $2.0 \mathrm{~m} / \mathrm{km}$, the relationship between the two is not stable and the standard deviation of three-meter-long straightedge is relatively loose. Moreover, the draft specification completed in 2005 by the Construction and Planning Agency, Ministry of the Interior, R.O.C., Taiwan, suggested that the smoothness of urban roads should be tested with the IRI as the testing standard. The acceptance evaluation standards of urban roads are detailed in Tables 4 and 5 [41]. Table 4 is mainly used as the acceptance evaluation standard when the original IRI value of urban roads is greater than $6.5 \mathrm{~m} / \mathrm{km}$. Table 5 is the acceptance evaluation standard for the construction of new urban roads or when the original IRI value is not greater than $6.5 \mathrm{~m} / \mathrm{km}$. Tables 4 and 5 divide the road into four grades, namely expressway, main and minor road, general minor road, and laneway. Taking the main and minor road in Table 4 as an example, if the original IRI is between $6.5-7.5 \mathrm{~m} / \mathrm{km}$, and the IRI after road leveling is less than $4.5 \mathrm{~m} / \mathrm{km}$, the evaluation result belongs to the qualified area. On the other hand, the current road smoothness inspection standards of the Taipei City Government are IRI $<2.8 \mathrm{~m} / \mathrm{km}$ for new construction urban roads, IRI $<5.5 \mathrm{~m} / \mathrm{km}$ for main road maintenance, and IRI $<6.5 \mathrm{~m} / \mathrm{km}$ for minor road maintenance. As other countries tend to have stricter pavement smoothness standards, this study uses the actual measurement data of urban roads to review the suitability of the above standards.

Table 4. Acceptance evaluation criteria for urban roads with an original IRI greater than $6.5 \mathrm{~m} / \mathrm{km}$ [41].

\begin{tabular}{ccccc}
\hline \multirow{2}{*}{ Road Grade } & $\begin{array}{c}\text { Original IRI Value } \\
(\mathbf{m} / \mathbf{k m})\end{array}$ & \multicolumn{3}{c}{ Evaluation Result $(\mathbf{m} / \mathbf{k m})$} \\
\cline { 3 - 5 } & Qualified Area & Correction Area & Redo Area \\
\hline Expressway & IRI $>7.5$ & IRI $\leq 4.5$ & $4.5<$ IRI $\leq 5.0$ & IRI $>5.0$ \\
& $6.5<$ IRI $\leq 7.5$ & IRI $\leq 4.0$ & $4.0<$ IRI $\leq 4.5$ & IRI $>4.5$ \\
\hline Main and minor road & IRI $>7.5$ & IRI $\leq 5.0$ & $5.0<$ IRI $\leq 5.5$ & IRI $>5.5$ \\
$($ Road width $>20 \mathrm{~m})$ & $6.5<$ IRI $\leq 7.5$ & IRI $\leq 4.5$ & $4.5<$ IRI $\leq 5.0$ & IRI $>5.0$ \\
\hline General minor road & IRI $>7.5$ & IRI $\leq 5.0$ & $5.0<$ IRI $\leq 5.5$ & IRI $>5.5$ \\
$(11 \mathrm{~m}<$ Road width $<20 \mathrm{~m})$ & $6.5<$ IRI $\leq 7.5$ & IRI $\leq 4.5$ & $4.5<$ IRI $\leq 5.0$ & IRI $>5.0$ \\
\hline Laneway & IRI $>7.5$ & IRI $\leq 5.5$ & $5.5<$ IRI $\leq 6.0$ & IRI $>6.0$ \\
$(8 \mathrm{~m}<$ Road width $<11 \mathrm{~m})$ & $6.5<$ IRI $\leq 7.5$ & IRI $\leq 5.0$ & $5.0<$ IRI $\leq 5.5$ & IRI $>5.5$ \\
\hline
\end{tabular}

Table 5. Acceptance evaluation criteria for construction of new urban roads or those with an original IRI not greater than $6.5 \mathrm{~m} / \mathrm{km}$ [41].

\begin{tabular}{|c|c|c|c|c|}
\hline \multirow{2}{*}{ Road Grade } & \multirow{2}{*}{$\begin{array}{l}\text { Original IRI Value } \\
(\mathrm{m} / \mathrm{km})\end{array}$} & \multicolumn{3}{|c|}{ Evaluation Result (m/km) } \\
\hline & & Qualified Area & Correction Area & Redo Area \\
\hline Expressway & $\mathrm{IRI} \leq 6.5$ & $\mathrm{IRI} \leq 3.2$ & $3.2<\mathrm{IRI} \leq 3.5$ & IRI $>3.5$ \\
\hline $\begin{array}{l}\text { Main and minor road } \\
\text { (Road width }>20 \mathrm{~m})\end{array}$ & $\mathrm{IRI} \leq 7.0$ & $\mathrm{IRI} \leq 3.5$ & $3.5<\mathrm{IRI} \leq 3.8$ & IRI $>3.8$ \\
\hline $\begin{array}{c}\text { General minor road } \\
(11 \mathrm{~m}<\text { Road width }<20 \mathrm{~m})\end{array}$ & $\mathrm{IRI} \leq 7.0$ & $\mathrm{IRI} \leq 3.5$ & $3.5<\mathrm{IRI} \leq 3.8$ & IRI $>3.8$ \\
\hline $\begin{array}{c}\text { Laneway } \\
(8 \mathrm{~m}<\text { Road width }<11 \mathrm{~m})\end{array}$ & $\mathrm{IRI} \leq 7.5$ & $\mathrm{IRI} \leq 4.0$ & $4.0<\mathrm{IRI} \leq 4.3$ & $\mathrm{IRI}>4.3$ \\
\hline
\end{tabular}

Among the 70 detected sections in the first phase of the Road Smoothing Project, 53 sections had an original IRI value less than or equal to $6.5 \mathrm{~m} / \mathrm{km}$. Calculated according to the acceptance evaluation criteria in Table 5, the evaluation results are shown in Table 6. Among them, 26 road sections were qualified areas, 5 road sections were correction areas, and 22 road sections were redo areas. Among the 70 sections in the first phase of the Road Smoothing Project, 17 sections had original IRI values greater 
than $6.5 \mathrm{~m} / \mathrm{km}$. According to the acceptance evaluation criteria in Table 4, the evaluation results were calculated, as shown in Table 7. Among them, 13 road sections were qualified areas, but 4 road sections were correction areas. From the above results, it can be seen that the qualified percentage of road sections with original IRI values greater than $6.5 \mathrm{~m} / \mathrm{km}$ after road leveling was $72.5 \%$, while the qualified percentage of road sections with original IRI values less than or equal to $6.5 \mathrm{~m} / \mathrm{km}$ after road leveling was only $49.1 \%$. This means that the current regulations of urban roads by the Construction and Planning Agency have stricter requirements for road sections with original IRI values less than or equal to $6.5 \mathrm{~m} / \mathrm{km}$ after road leveling. In contrast, according to the current road smoothness inspection standards of the Taipei City government, the IRI values of all detected sections after road leveling meet the requirements.

As mentioned earlier, the IRI thresholds used around the world are quite different. The maximum allowable driving speed on the road is the key factor. The speed of the test vehicle in this study was between 13.7 and $37.4 \mathrm{~km} / \mathrm{h}$. Therefore, if the driving speed is $40 \mathrm{~km} / \mathrm{h}$, the speed-related IRI thresholds can be determined from the ride quality level in Table 1 [33]. The results are shown in Figure 11. An IRI less than $2.86 \mathrm{~m} / \mathrm{km}$ means that the ride quality rating is "very good"; an IRI between 2.86 and $4.49 \mathrm{~m} / \mathrm{km}$ means that the ride quality rating is "good"; an IRI between 4.50 and $5.69 \mathrm{~m} / \mathrm{km}$ means that the ride quality rating is "fair"; an IRI between 5.70 and $8.08 \mathrm{~m} / \mathrm{km}$ means that the ride quality rating is "mediocre"; an IRI greater than $8.08 \mathrm{~m} / \mathrm{km}$ means that the ride quality rating is "poor". In addition, it can be seen from the distribution of the IRI range in Figure 11 that more than $60 \%$ of the detected road sections had poor smoothness prior to leveling, which may make passers-by feel "quite uncomfortable", but after leveling, no IRI of any road section fell into this range. The IRI of the road section falling into the "comfortable" range increased significantly from $4.39 \%$ before leveling to $85.83 \%$, indicating that the smoothness after leveling improved significantly. The histograms of the calculated IRI distribution of the 171 asphalt concrete pavement sections are shown in Figure 12. It can be clearly seen that $84.80 \%$ of repaired roads had an IRI $<4.5 \mathrm{~m} / \mathrm{km}$. Based on the above results, it is recommended that the IRI threshold value for road rehabilitation in Taipei City be set at $4.50 \mathrm{~m} / \mathrm{km}$. This threshold is higher than Taiwan's current pavement smoothness inspection standards (i.e., IRI $<3.5 \mathrm{~m} / \mathrm{km}$ ) for general roads, but lower than Taipei City's road smoothness inspection standards (i.e., IRI $<5.5 \mathrm{~m} / \mathrm{km}$ for main road maintenance and IRI $<6.5 \mathrm{~m} / \mathrm{km}$ for minor road maintenance). Considering the traffic factors, such as the manhole and hand hole problems in the metropolitan areas, it should be a reasonable standard. In particular, moderately lowering the IRI threshold for road maintenance in Taipei City can conform to the trend that other countries have set for gradually tightening the IRI threshold for roads.

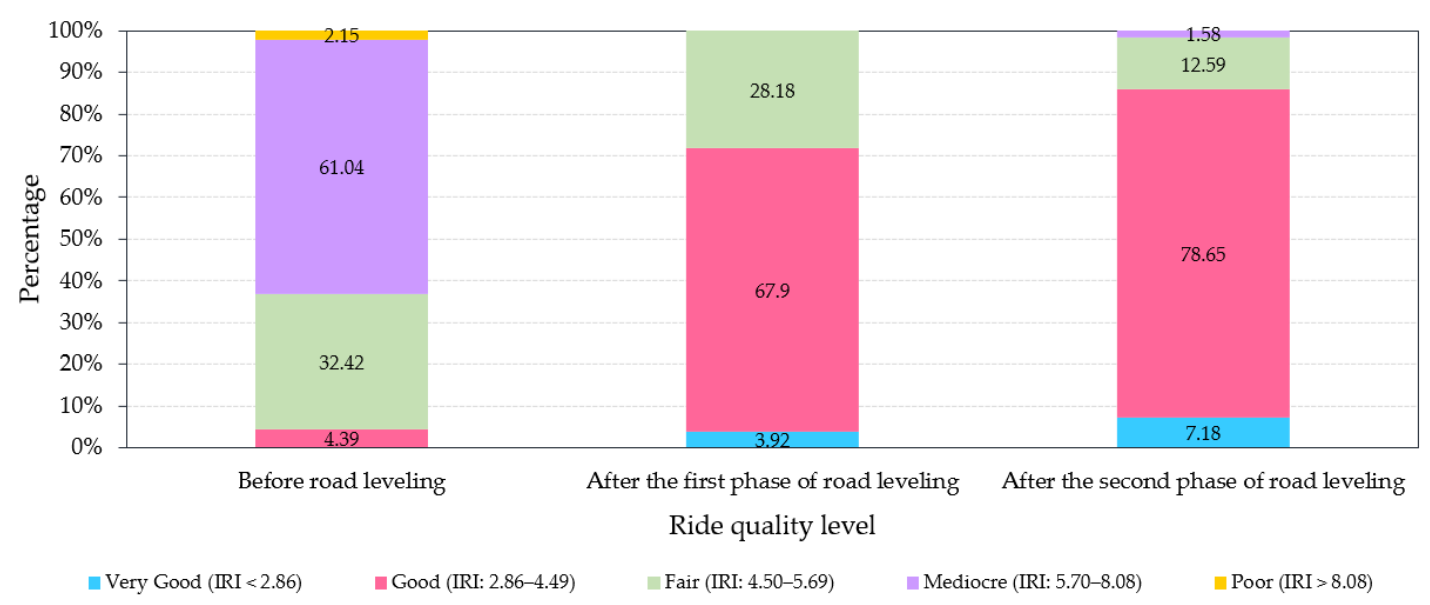

Figure 11. Comparison of IRI values before and after the Road Smoothing Project. 
Table 6. Evaluation result of detected sections with original IRI values not greater than $6.5 \mathrm{~m} / \mathrm{km}$.

\begin{tabular}{|c|c|c|c|c|}
\hline $\begin{array}{c}\text { Road Section } \\
\text { Number }\end{array}$ & $\begin{array}{l}\text { IRI Value Before } \\
\text { Leveling }\end{array}$ & $\begin{array}{l}\text { IRI Value After } \\
\text { Leveling }\end{array}$ & $\begin{array}{l}\text { Length of Road } \\
\text { Section (m) }\end{array}$ & Evaluation Result \\
\hline 1 & 3.13 & 3.45 & 4000 & Qualified area \\
\hline 2 & 3.66 & 3.83 & 4100 & Redo area \\
\hline 3 & 3.01 & 3.25 & 2900 & Qualified area \\
\hline 4 & 6.14 & 3.11 & 2500 & Qualified area \\
\hline 6 & 5.98 & 3.79 & 4600 & Correction area \\
\hline 7 & 4.78 & 4.18 & 2400 & Redo area \\
\hline 8 & 5.69 & 4.04 & 3600 & Redo area \\
\hline 9 & 5.37 & 4.03 & 5000 & Redo area \\
\hline 10 & 7.12 & 4.57 & 3100 & Redo area \\
\hline 11 & 6.01 & 4.63 & 2700 & Redo area \\
\hline 12 & 6.14 & 2.92 & 1400 & Qualified area \\
\hline 14 & 5.71 & 2.88 & 5300 & Qualified area \\
\hline 15 & 7.21 & 5.05 & 2700 & Redo area \\
\hline 16 & 7.6 & 5.07 & 5600 & Redo area \\
\hline 17 & 6.12 & 4.57 & 3750 & Redo area \\
\hline 18 & 6.12 & 5.07 & 3750 & Redo area \\
\hline 20 & 5.44 & 3.77 & 2100 & Correction area \\
\hline 21 & 6.48 & 4.63 & 2600 & Redo area \\
\hline 22 & 3.99 & 3.62 & 3500 & Correction area \\
\hline 25 & 5.37 & 3.06 & 3200 & Qualified area \\
\hline 26 & 5.44 & 3.35 & 2800 & Qualified area \\
\hline 27 & 6.2 & 3.83 & 4300 & Redo area \\
\hline 28 & 5.3 & 3.13 & 1300 & Qualified area \\
\hline 29 & 6.36 & 3.24 & 2200 & Qualified area \\
\hline 30 & 5.8 & 3.01 & 1500 & Qualified area \\
\hline 31 & 5.81 & 4.01 & 1400 & Redo area \\
\hline 32 & 5.14 & 3.29 & 3500 & Qualified area \\
\hline 33 & 4.8 & 3.38 & 4000 & Qualified area \\
\hline 34 & 5.47 & 3.45 & 4300 & Qualified area \\
\hline 35 & 6.23 & 4.5 & 1700 & Redo area \\
\hline 36 & 4.63 & 3.44 & 2000 & Qualified area \\
\hline 37 & 4.63 & 2.97 & 2300 & Qualified area \\
\hline 39 & 4.4 & 2.95 & 2400 & Qualified area \\
\hline 40 & 5.44 & 3.35 & 2800 & Qualified area \\
\hline 41 & 5.31 & 3.96 & 3200 & Redo area \\
\hline 47 & 5.22 & 3.3 & 2100 & Qualified area \\
\hline 48 & 4.6 & 3.1 & 2200 & Qualified area \\
\hline 49 & 6.14 & 2.92 & 1400 & Qualified area \\
\hline 52 & 6.17 & 3.78 & 6400 & Correction area \\
\hline 53 & 5.26 & 2.47 & 1200 & Qualified area \\
\hline 54 & 6.04 & 3.81 & 700 & Redo area \\
\hline 55 & 4.77 & 2.8 & 1600 & Qualified area \\
\hline 56 & 5.72 & 2.66 & 2400 & Qualified area \\
\hline 57 & 4.9 & 2.62 & 2700 & Qualified area \\
\hline 60 & 5.73 & 3.49 & 1800 & Qualified area \\
\hline 61 & 5.67 & 3.44 & 3700 & Qualified area \\
\hline 64 & 5.98 & 4.3 & 3500 & Redo area \\
\hline 65 & 5.16 & 4.44 & 2400 & Redo area \\
\hline 66 & 5.16 & 3.73 & 2400 & Correction area \\
\hline 67 & 5.16 & 4.37 & 2200 & Redo area \\
\hline 68 & 4.94 & 3.89 & 3600 & Redo area \\
\hline 69 & 4.9 & 4.14 & 1500 & Redo area \\
\hline 70 & 5.63 & 4.57 & 2300 & Redo area \\
\hline
\end{tabular}


Table 7. Evaluation result of detected road sections with original IRI values greater than $6.5 \mathrm{~m} / \mathrm{km}$.

\begin{tabular}{ccccc}
\hline $\begin{array}{c}\text { Road Section } \\
\text { Number }\end{array}$ & $\begin{array}{c}\text { IRI Value Before } \\
\text { Leveling }\end{array}$ & $\begin{array}{c}\text { IRI Value After } \\
\text { Leveling }\end{array}$ & $\begin{array}{c}\text { Length of Road } \\
\text { Section }(\mathbf{m})\end{array}$ & Evaluation Result \\
\hline 5 & 6.7 & 3.52 & 2600 & Qualified area \\
13 & 6.61 & 4.44 & 2300 & Qualified area \\
19 & 7.63 & 4.3 & 1000 & Qualified area \\
23 & 7.58 & 3.87 & 900 & Qualified area \\
24 & 7.27 & 4.56 & 1400 & Correction area \\
38 & 7.29 & 4.63 & 1350 & Correction area \\
42 & 7.88 & 4.86 & 2100 & Qualified area \\
43 & 7.39 & 4.35 & 1400 & Qualified area \\
44 & 7.39 & 4.57 & 1400 & Correction area \\
45 & 7.32 & 4.38 & 1500 & Qualified area \\
46 & 8.89 & 4.77 & 1000 & Qualified area \\
50 & 7.24 & 4.82 & 1500 & Correction area \\
51 & 7.85 & 4.84 & 3200 & Qualified area \\
58 & 6.95 & 3.73 & 1700 & Qualified area \\
59 & 7.29 & 3.44 & 2300 & Qualified area \\
62 & 6.9 & 4.32 & 900 & Qualified area \\
63 & 6.63 & 4.08 & 2200 & Qualified area \\
\hline
\end{tabular}
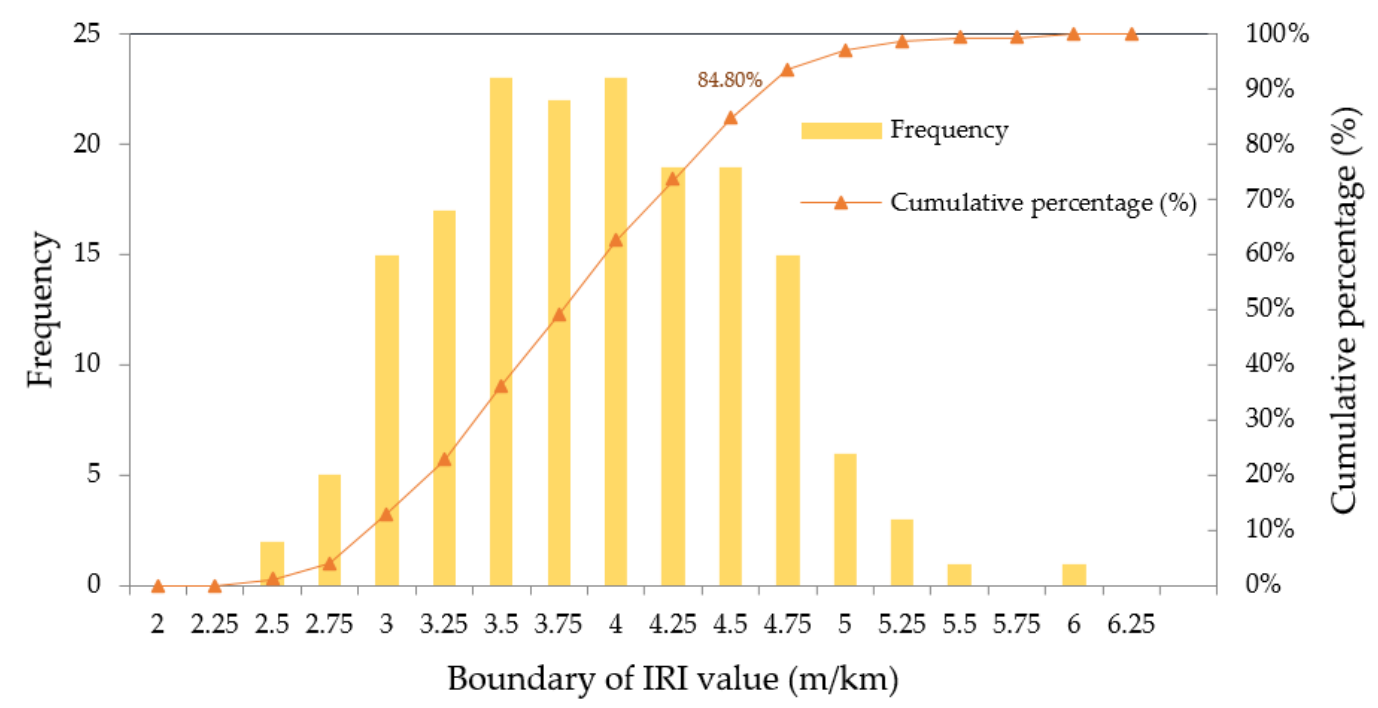

Figure 12. Histogram and cumulative curve of IRI values for the 171 asphalt concrete pavement sections.

\subsection{Analysis of the Effectiveness of Road Leveling}

Generally speaking, the speed of urban roads is low, so comfortable driving can still be achieved under high IRI values. If acceptable IRI thresholds for urban roads with various speed limits can be set, it will help road managers to objectively compare the driving quality of roads with different speed limits. Moreover, in the case of limited budgets, in order to maximize the effectiveness of road maintenance funds, it is necessary to consider which roads should be improved first to improve the overall service standard. However, it is not an easy task to decide how to make the most effective use of limited road maintenance funds. According to this study, if the smoothness classification before road leveling is used as the basis, the average improvement in IRI can be calculated. The results are shown in Table 8 and Figure 13. It can be seen from Table 8 and Figure 13 that when the original IRI value of the road is less than $3 \mathrm{~m} / \mathrm{km}$ and the smoothness is quite good, the IRI value of the road is not significantly improved after the improvement is completed. When the original smoothness value is poor, the improvement is more obvious. From the above discussion, it can be seen that if priority is given to road sections with poor smoothness, the number of road sections with poor service quality 
will be effectively reduced and the overall road service level will be improved. Using Figure 12 and some basic information about the road, we can arrange the budget for the number of roads with IRI values greater than the threshold value, or estimate how much budget is needed to improve the roads with an IRI above a certain value.

Table 8. Effectiveness of the first phase of the Road Smoothing Project.

\begin{tabular}{cccc}
\hline $\begin{array}{c}\text { Classification of } \\
\text { IRI Value }\end{array}$ & $\begin{array}{c}\text { IRI Value Before } \\
\text { Road Leveling }\end{array}$ & $\begin{array}{c}\text { IRI Value After } \\
\text { Road Leveling }\end{array}$ & $\begin{array}{c}\text { Average IRI After } \\
\text { Improvement }\end{array}$ \\
\hline IRI $<4$ & 3.45 & 3.54 & -0.09 \\
$4 \leq$ IRI $<5$ & 4.74 & 3.35 & 1.39 \\
$5 \leq$ IRI $<6$ & 5.50 & 3.58 & 1.92 \\
$6 \leq$ IRI $<7$ & 6.35 & 3.95 & 2.40 \\
$7 \leq$ IRI $<8$ & 7.43 & 4.52 & 2.91 \\
IRI $\geq 8$ & 8.89 & 4.77 & 4.12 \\
\hline
\end{tabular}

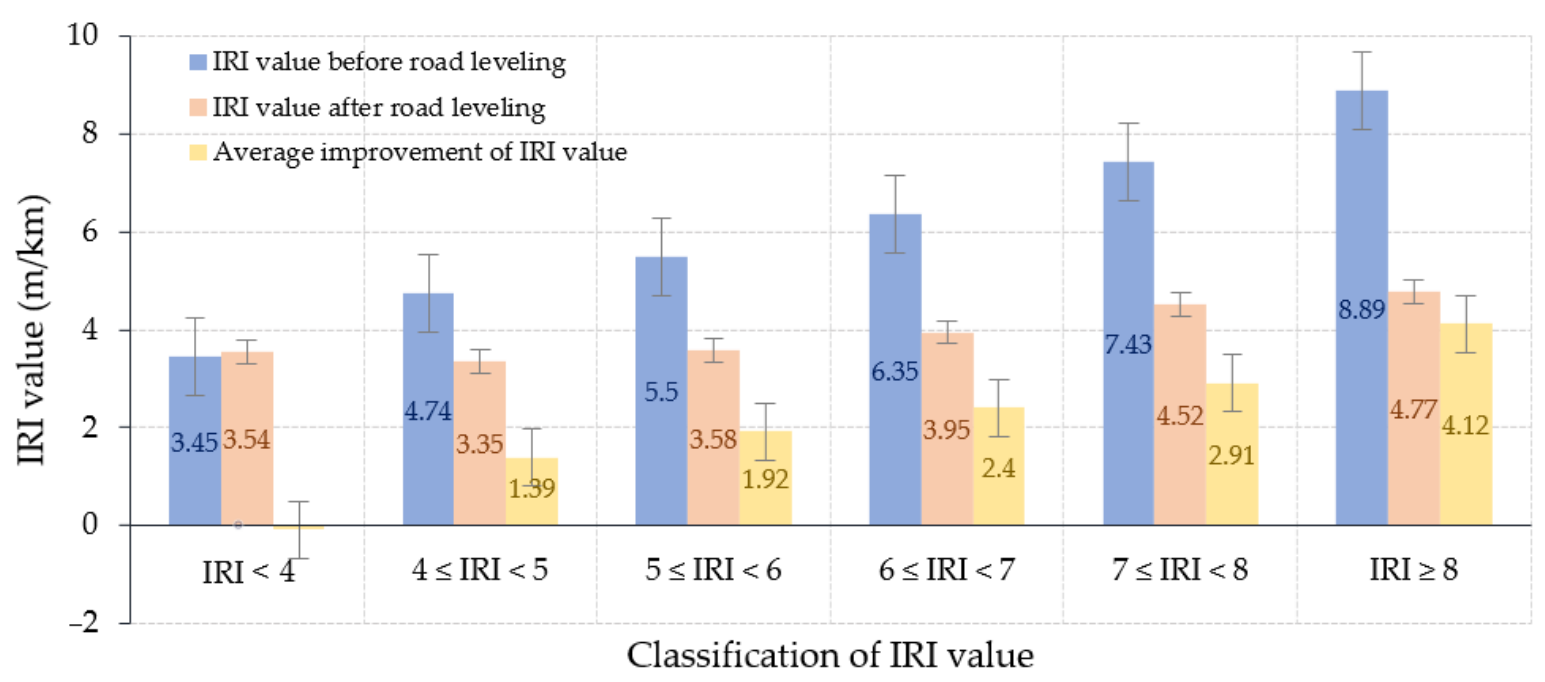

Figure 13. Average improvement of IRI values before and after the first phase of the Road Smoothing Project.

\section{Conclusions}

This research detected the longitudinal profiles of asphalt concrete pavements in Taipei City and examined the threshold values of acceptance for pavement smoothness to determine whether there is a need to reasonably adjust the current acceptance threshold for maintenance and rehabilitation scheduling. Based on the analysis results, the following conclusions can be obtained.

1. The IRI value before road leveling was mainly distributed between 5 and $8 \mathrm{~m} / \mathrm{km}$, while the IRI value after road leveling was mainly distributed between 3 and $5 \mathrm{~m} / \mathrm{km}$. The IRI value of the detected road section showed a downward trend, indicating that the implementation of the road leveling project had a significant effect on improving road smoothness.

2. According to the histogram and cumulative curve of IRI values for the 171 asphalt concrete pavement sections, $84.80 \%$ of repaired roads had an IRI of $<4.5 \mathrm{~m} / \mathrm{km}$. Accordingly, it is recommended to set the IRI threshold for road rehabilitation in Taipei City to $4.50 \mathrm{~m} / \mathrm{km}$. This threshold is higher than Taiwan's current ordinary road surface smoothness inspection standard. However, the speed of urban roads is relatively low, and comfortable driving can still be achieved under high IRI values. Therefore, considering the characteristics of traffic factors in metropolitan areas, this should be a reasonable standard.

3. The cumulative distribution curve of IRI values can quickly estimate the number of kilometers of roads that must be maintained, and by using sorting and some basic information about the 
road conditions, we can quickly determine the section requiring maintenance and estimate the maintenance budget.

4. Moderately lowering the IRI threshold for road maintenance in Taipei City can conform to the trend that other countries have set for gradually tightening the IRI threshold for roads.

Author Contributions: Conceptualization, S.-L.C.; methodology, C.-H.L.; software, S.-L.C.; validation, S.-L.C. and C.-H.L.; formal analysis, C.-W.T. and C.-K.C.; investigation, S.-L.C. and C.-H.L.; resources, L.-P.C.; data curation, L.-P.C.; writing—original draft preparation, C.-H.L. and L.-P.C.; writing—review and editing, C.-W.T.; visualization, C.-W.T. and C.-K.C.; supervision, S.-L.C.; project administration, S.-L.C.; funding acquisition, S.-L.C. All authors have read and agreed to the published version of the manuscript.

Funding: The research was funded by the Ministry of Science and Technology of Taiwan grant number MOST 105-2221-E-027-018-MY3.

Acknowledgments: The authors sincerely thank the Ministry of Science and Technology of Taiwan for funding this research work, and thank Integrated Engineering Evaluations for providing some instrument photos. In addition, the authors thank Guo-ping Zhou, General Secretary of New Construction Office, Public Works Department, Taipei City Government for his valuable assistance.

Conflicts of Interest: The authors declare no conflict of interest.

\section{References}

1. Papagiannakis, A.T.; Masad, E.A. Pavement Design and Materials; John Wiley \& Sons, Inc.: Hoboken, NJ, USA, 2012.

2. Federal Highway Administration (FHWA). Pavement Smoothness Technologies. 2006. Available online: http://www.fhwa.dot.gov/teams/pavement/pave_5psm.cfm (accessed on 21 July 2020).

3. Paterson, W.D.O. International Roughness Index: Relationship to Other Measures of Roughness and Riding Quality. Transportation Research Record 1084. In Proceedings of the 65th Annual Meeting of the Transportation Research Board, Washington, DC, USA, 13-16 January 1986.

4. Sayers, M.W.; Gillespie, T.D.; Queiroz, C.A.V. The International Road Roughness Experiment: A Basis for Establishing a Standard Scale for Road Roughness Measurement; Transportation Research Record 1084; Transportation Research Board, National Research Council: Washington, DC, USA, 1986.

5. Sayers, M.W.; Gillespie, T.D.; Queiroz, C.A.V. International Experiment to Establish Correlations and Standard Calibration Methods for Road Roughness Measurements; Technical Paper Number 45; World Bank: Washington, DC, USA, 1986.

6. Sayers, M.W.; Gillespie, T.D.; Paterson, W.D. Guidelines for the Conduct and Calibration of Road Roughness Measurements; Technical Paper No. 46; World Bank: Washington, DC, USA, 1986.

7. Al-Omari, B.; Darter, M.I. Relationship between International Roughness Index and Present Serviceability Rating; Transportation Research Record 1435; TRB: Washington, DC, USA, 1994.

8. Sayers, M.W. On the Calculation of International Roughness Index from Longitudinal Road Profile. Available online: https://trid.trb.org/view/452992 (accessed on 30 September 2020).

9. Sayers, M.W.; Karamihas, S.M. The Little Book of Profiling: Basic Information about Measuring and Interpreting Road Profiles; University of Michigan Transportation Research Institute: Ann Arbor, MI, USA, 1998.

10. Hall, K.T.; Munoz, C.E.C. Estimation of Present Serviceability Index from International Roughness Index; Transportation Research Record 1655; Transportation Research Board: Washington, DC, USA, 1999.

11. Swanlund, M. Enhancing Pavement Smoothness. Public Roads 2002, 64, 20-22.

12. Du, Y.; Liu, C.; Wu, D.; Jiang, S. Measurement of International Roughness Index by Using Z-Axis Accelerometers and GPS. Math. Probl. Eng. 2014, 928980. [CrossRef]

13. Arhin, S.A.; Williams, L.N.; Ribbiso, A.; Anderson, M.F. Predicting Pavement Condition Index Using International Roughness Index in a Dense Urban Area. J. Civil Eng. Res. 2015, 5, $10-17$.

14. ASTM International. Standard Practice for Computing International Roughness Index of Roads from Longitudinal Profile Measurements; ASTM E1926-08; ASTM International: West Conshohocken, PA, USA, 2015.

15. Loprencipe, G.; Zoccali, P. Use of Generated Artificial Road Profiles in Road Roughness Evaluation. J. Mod. Transp. 2017, 25, 24-33. [CrossRef]

16. Múčka, P. International roughness index specifications around the world. Road Mater. Pavement Des. 2017, 18, 929-965. [CrossRef] 
17. Loprencipe, G.; Pantuso, A.; Di Mascio, P. Sustainable pavement management system in urban areas considering the vehicle operating costs. Sustainability 2017, 9, 453. [CrossRef]

18. Nguyen, L.H. Research on the Correlation Between International Roughness Index (IRI) and Present Serviceability Index (PSI), Recommendations on Evaluation Rates in Vietnam's Conditions. Int. J. Eng. Res. Technol. 2017, 6, 266-271.

19. Uechi, S.T.; Uechi, H. The Profiling of International Roughness Index (IRI) Based on Lagrangian Method. World J. Eng. Technol. 2018, 6, 885-902. [CrossRef]

20. Singh, D.K.; Gundaliya, P.J. Flexible Pavement Evaluation Using Profilometer for Unevenness. Int. Res. J. Eng. Technol. 2018, 5, 1024-1028.

21. Zang, K.; Shen, J.; Huang, H.; Wan, M.; Shi, J. Assessing and Mapping of Road Surface Roughness based on GPS and Accelerometer Sensors on Bicycle-Mounted Smartphones. Sensors 2018, 18, 914. [CrossRef]

22. Kırbaş, U. IRI Sensitivity to the Influence of Surface Distress on Flexible Pavements. Coatings 2018, 8, 271. [CrossRef]

23. Mahmoudzadeh, A.; Golroo, A.; Jahanshahi, M.R.; Firoozi Yeganeh, S. Estimating Pavement Roughness by Fusing Color and Depth Data Obtained from an Inexpensive RGB-D Sensor. Sensors 2019, 19, 1655. [CrossRef] [PubMed]

24. Loprencipe, G.; Zoccali, P.; Cantisani, G. Effects of Vehicular Speed on the Assessment of Pavement Road Roughness. Appl. Sci. 2019, 9, 1783. [CrossRef]

25. Mirtabar, Z.; Golroo, A.; Mahmoudzadeh, A.; Barazandeh, F. Development of a crowdsourcing-based system for computing the international roughness index. Int. J. Pavement Eng. 2020. [CrossRef]

26. Hossain, M.; Gopisetti, L.S.P.; Miah, M.S. Artificial neural network modelling to predict international roughness index of rigid pavements. Int. J. Pavement Res. Technol. 2020, 13, 229-239. [CrossRef]

27. Liu, Y.; Du, T.; Xie, J. Development of the flatness detection system for cement concrete pavement construction phase. Mater. Sci. Eng. 2020, 892, 012040. [CrossRef]

28. Song, Y.; Chen, R. Analysis method of vehicle Vibration response caused by pavement roughness. J. Traffic Transp. Eng. 2007, 7, 39-43.

29. Wang, J.; Ma, J.; Ma, R. Study on calculation of dynamic displacement from time-frequency integration of acceleration. Comput. Sci. 2010, 37, 201-207.

30. Thite, A.N.; Banvidi, S.; Ibicek, T.; Bennett, L. Suspension parameter estimation in the frequency domain using a matrix inversion approach. Veh. Syst. Dyn. 2011, 49, 1803-1822. [CrossRef]

31. Loprencipe, G.; Zoccali, P. Ride Quality Due to Road Surface Irregularities: Comparison of Different Methods Applied on a Set of Real Road Profiles. Coatings 2017, 7, 59. [CrossRef]

32. Cantisani, G.; Loprencipe, G. Road roughness and whole body vibration: Evaluation tools and comfort limits. J. Transp. Eng. 2010, 136, 818-826. [CrossRef]

33. Yu, J.; Chou, E.; Yau, J.T. Development of speed-related ride quality thresholds using international roughness index. Transp. Res. Rec. J. Transp. Res. Board. 2006, 1, 47-53. [CrossRef]

34. Bridgelall, R.; Huang, Y.; Zhang, Z.; Deng, F. Precision enhancement of pavement roughness localization with connected vehicles. Meas. Sci. Technol. 2016, 27, 025012. [CrossRef]

35. Zhang, Z.; Sun, C.; Bridgelall, R.; Sun, M. Application of a machine learning method to evaluate road roughness from connected vehicles. J. Transp. Eng. Part B Pavements 2018, 144, 04018043. [CrossRef]

36. Abeygunawardhana, C.; Sandamal, R.M.K.; Pasindu, H.R. Identification of the Impact on Road Roughness on Speed Patterns for Different Roadway Segments. In Proceedings of the 2020 Moratuwa Engineering Research Conference (MERCon), Moratuwa, Sri Lanka, 28-30 July 2020.

37. Meyer, F.J.; Ajadi, O.A.; Hoppe, E.J. Studying the Applicability of X-Band SAR Data to the Network-Scale Mapping of Pavement Roughness on US Roads. Remote Sens. 2020, 12, 1507. [CrossRef]

38. ASTM International. Standard Test Method for Measuring the Longitudinal Profile of Traveled Surfaces with an Accelerometer-Established Inertial Profiling Reference; ASTM E950/E950M-09(2018); ASTM International: West Conshohocken, PA, USA, 2018.

39. Taipei City Government. Phase II Test Results Report of Urban Road Smoothness; Public Works Department, Taipei City Government: Taipei, Taiwan, 2020. (In Chinese) 
40. Chou, C.P. Modification of the Urban Road Pavement Damage Detection System and Smoothness Acceptance Mechanism; Research Report Commissioned by the Construction Department; Construction and Planning Agency, Ministry of the Interior, R.O.C.: Taipei, Taiwan, 2011. (In Chinese)

41. Specification for Acceptance of Urban Road Smoothness (Draft). Construction and Planning; Ministry of the Interior, R.O.C.: Taipei, Taiwan, 2005. (In Chinese)

Publisher's Note: MDPI stays neutral with regard to jurisdictional claims in published maps and institutional affiliations.

(C) 2020 by the authors. Licensee MDPI, Basel, Switzerland. This article is an open access article distributed under the terms and conditions of the Creative Commons Attribution (CC BY) license (http://creativecommons.org/licenses/by/4.0/). 